\title{
ERJ
}

Engineering Research Journal

Faculty of Engineering

Menoufia University

\section{COMPUTATIONAL AND EXPERIMENTAL STUDY ON THE WATER-JET PUMP PERFORMANCE UNDER DIFFERENT GEOMETRICAL AND OPERATIONAL PARAMETERS}

\author{
M. Nasr*, M.A. Hosien*, E.M. Wahba* and A.A.A. Sheha** \\ * Mechanical Power Engineering Department, Faculty of Engineering, Menoufia University, Shebin El-Kom Egypt \\ ** Rotating Equipment Engineer, Petrogulfmisr Oil Company, 10, St. 250 Sarayat El-Maadi, Cairo, Egypt \\ **E-mail Address (Corresponding Author): engineer_sheha@yahoo.com
}

\begin{abstract}
The aim of the present study is to investigate the performance of jet pump. The effect of geometrical and operational parameters on the jet pumps efficiency were determined numerically and experimentally. Numerical investigation was held firstly to determine the effect of diffuser angle, mixing chamber length, pump area ratio and driving nozzle position on the jet pump efficiency. Commercial computational fluid dynamics (CFD) solver ANSYS R 15.0-FLUENT using SST-turbulence model was used. The numerical results showed that jet pump efficiency increases with decreasing both of diffuser angle and mixing chamber length up to a certain value and then pump efficiency decreases. Also, jet pump efficiency increases with increasing pump area ratio up to a certain value and then pump efficiency decreases. It was found that maximum computed efficiency is $37.82 \%$ at the pump area ratio of 0.271 and a pressure ratio of 0.317 . In addition, the numerical results showed that the optimum relative length of mixing chamber is 5.48 and the optimum value for diffuser angle at which the efficiency is a maximum value is $5^{\circ}$. Experimental tests were conducted to study the effects of various geometrical and operational parameters on the performance of the jet pumps. A test rig was constructed using the optimum design from the numerical results. The physics of flow within axial-water jet pumps can be analyzed and optimized easily by using the CFD, 2D technique with a satisfactory accuracy in order to save computational time and cost. The CFD's results were found to agree well with actual values obtained from the experimental results.

در اسة أداء المضخة النافورية عددياً و عملياً تحت ثأثثر مختلف العو امل الهندسية والعو امل التشغيلية

تهدف الدر اسة الحالية إلى دراسة أداء المضخة النافورية. تم تحديد تأثير العو امل الهندسية والعو امل التشغيلية على أداء المضخة النافورية عددياً و عملياً. تم

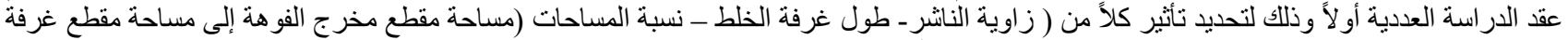

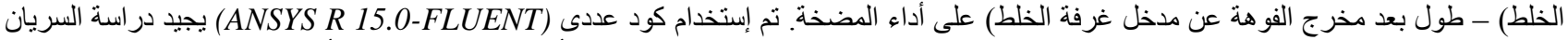

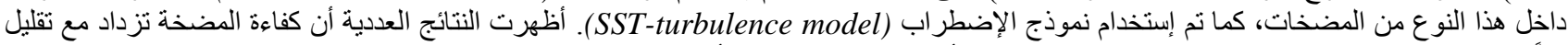

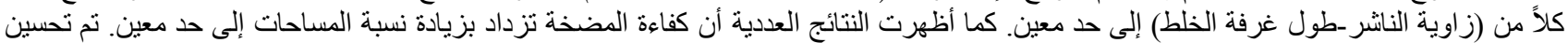

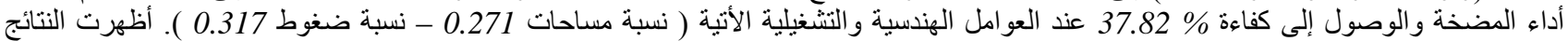

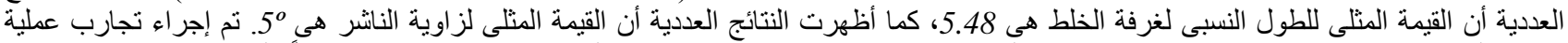

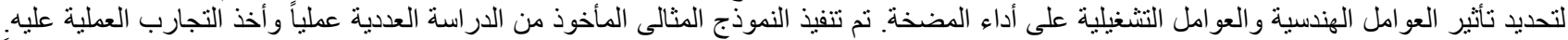

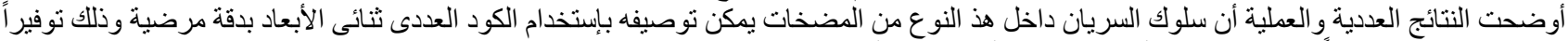

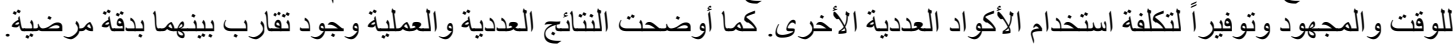

Keywords: Jet pump; CFD; Pump efficiency; Geometrical parameters; Operational parameters

\section{INTRODUCTION}

Jet pumps have come into widespread use in many branches of engineering. Jet pumps are simple devices in terms of design, easy to fabricate and repair, perform reliably, do not require preliminary priming prior to start up, and permit the pumping of contaminated liquid. The overall efficiency of the jet pump is low compared with most of the other types of pumps with moving parts. Their efficiencies are extremely affected by the geometrical and operational parameters of the jet pumps.
Chamlong and Aoki [1] developed a numerical prediction to the optimum mixing throat length for driving nozzle position of the central jet pump. They investigated flow pattern and pressure distribution in the pump with the change of position of the driving nozzle by three-dimensional numerical analysis using RNG k- $\varepsilon$ turbulent flow method. The results concluded that, when nozzle to mixing throat ratio (d/D) of jet pump is 0.6 the maximum efficiency is obtained.

Hammoud [2] presented experimental observations for the performance of a water- jet pump with two different suction configurations and designs. His results showed 
that, the optimum value for nozzle-to-throat spacing to nozzle diameter ratio is about 1.25 and the optimum value for motive fluid pressure is about 1.5 bar at a distance from the pump inlet ( $\mathrm{x}$ ) of 1.25.

El-Sawaf et al. [3] carried out an experimental study to investigate the effect of area ratio, mixing chamber length, diffuser angle and nozzle to throat spacing on the jet pump performance with different flow rates and motive pressures. Their results illustrated that the optimum value for $\mathrm{x}$ for pumping water is about 1 .

Vyas and Kar [4] suggested general method for the optimum design of the components of water jet pump and consequently for the entire pumping unit.

Teaima and Meakhail [5] investigated experimentally and numerically the effects of driving pressure and the nozzle spacing on the pump performance. They concluded that the maximum efficiency of $25.6 \%$ occurs at $\mathrm{x}=0.5$ and the pumping liquid prone to cavitation as the nozzle to throat spacing is reduced to zero. They suggested a diffuser angle of $5.5^{\circ}$.

Aldas and Yapici [6] carried out numerical simulation study to determine how the scaling-up, downscaling and change in the absolute and relative roughness would impact on the energy efficiency of jet pumps. They conducted a preliminary study on a full-scale jet pump using four turbulence models the realizable $\mathrm{k}-\varepsilon$ model, RSM model, SST k- $\omega$ model and transition SST model. They compared all models results with the experimental results. The comparison illustrated that the transition SST model provided more accurate results than other models. Also, they concluded that CFD appears to be the most appropriate tool for model studies of jet pumps.

Cunningham and Dopkin [7] suggested an expression that an optimum throat length can be determined. They carried out several experiments to investigate the effect of changing nozzle shapes on pump efficiency. They recommended a mixing throat length of $6 \mathrm{D}_{\text {th }}$.

According to Prabkeao and Aoki [8] the throat length decreases as the nozzle-throat ratio increases. In addition as the mixing throat length also increases the flow-ratio decreases when the nozzle location is closer to throat entrance.

Hansen and Kinnavy [9] carried out experimental work to determine the optimum design parameters of water jet pumps. They found that the optimum value of $\mathrm{x}$ increases somewhat with area ratio.

El-Hayek and Hammoud [10] presented investigation that deals with the application of advanced numerical techniques to the prediction of the overall performance (head ratio and efficiency) of liquid jet liquid pumps. They carried out the task by solving the flow equations, along with two turbulence models, namely, the $\mathrm{k}-\varepsilon$ model and the Reynolds stress model, using a finite volume approach with the appropriate boundary conditions. They concluded that the CFD techniques can be used in the field of jet pumps to provide insights concerning the physics of the flow and as a result to contribute the possible improvement of the overall design.

Winoto et al. [11] examined non-circular nozzles such as squared and triangular. Their results showed that all the examined configurations have lower efficiency compared to the circular shaped.

Zou et al. [12] carried out numerical simulations in different gravity fields to seek the differences of the performance between the horizontal installation and the vertical installation of the jet pump. Three turbulence models were used to calculate a 3D single-phase flow field in the jet pump and compared the results with the experimental data to validate the simulation. They concluded that the efficiency of the vertical inlet is the highest.

Brijesh and Sagar [13] carried out experimental study to show the effect of change in geometrical parameter (Diffuser angle) on the performance of jet pump. The experimental results showed that, changing the diffuser angle will affect jet pump behaviour. The maximum suction lift of the jet pump and the venturi of diffuser angle of $5^{\circ}$ give the highest efficiency.

Xiaogang et al. [14] investigated numerically the characteristics of the internal flow for both conventional and improved annular water-air jet pump. They concluded that the numerical comparison demonstrated an increase of approximately $10 \%$ pumping performance of improved annular water jet pump compared with the conventional pump.

It appears that there is a lack on the published work concerning an optimization study on water jet pumps using CFD, 2D techniques over a large range of area ratio. Therefore, the main purpose of the present numerical and experimental studies is to investigate numerically the effects of the jet pump area ratio, diffuser angle, length of the mixing chamber and nozzle relative position on the pump performance using CFD simulation. To assess the validity of the simulation by comparing the CFD, $2 \mathrm{D}$ results with the experimental results.

\section{FLOW MODELLING IN JET PUMP}

\subsection{The physical model}

Jet pump with a cylindrical mixing chamber which is the basis of the simulation study is schematically in Fig. 1 with scale (1/1) and the main dimensions are given below the Figure. All fluids flow through the inlet and outlet of the pump are in the axial direction. In axialwater jet pump, the entrained flow enters symmetrically in a rotational motion to the suction chamber and then the suction nozzle. The most important factor of efficiency improvement is the suction type. In the present study the inner surfaces of the pump parts can be assumed to be hydraulically 
smooth since the mixing chamber and suction chamber is made from a new drawn pipe $\left(\mathrm{K}_{\mathrm{s}}=\right.$ $0.00015 \mathrm{~mm})$. Also, the inner surfaces of the diffuser $\left(\mathrm{K}_{\mathrm{s}}=0.00015 \mathrm{~mm}\right)$. The motive nozzle, the suction nozzles and diffuser are machined much more precisely than the new pipe. The axial-jet pump casings that have various dimensions used in the CFD simulation using 2D solid modelling were designed using Design Modeler software in an ANSYS Fluent Workbench platform.

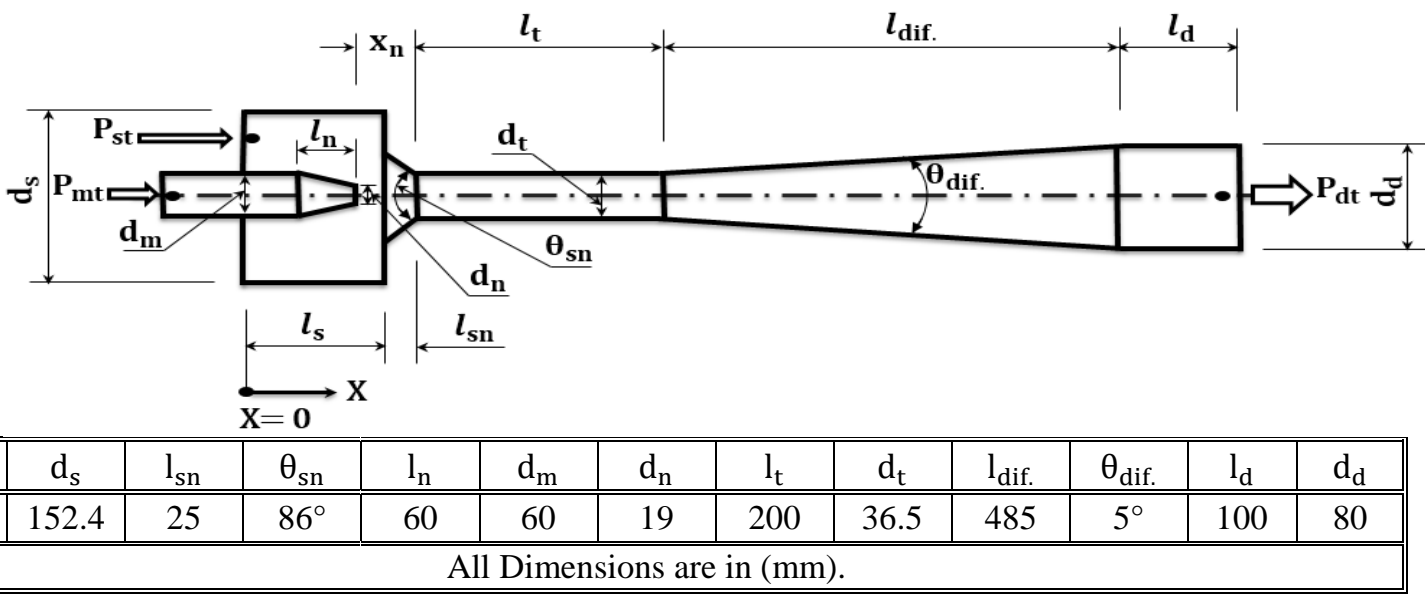

Figure 1 Axial-jet pump geometry and dimensions with scale (1/1) at which the obtained maximum theoretical efficiency.

\subsection{The numerical model}

The academic version of the ANSYS Fluent R 15.0 CFD code is used for all computations which employs a finite volume discretization. The two-dimensional steady flow of water through the pump is used for numerical simulation. The numerical simulation for the axial-jet pump is conducted in order to study the effect of operational and geometrical parameters on axialwater jet pump and also to simulate flow behaviour through the pump under these different geometrical and operational parameters. In the present study, the transition SST turbulence model is suggested according to the recommendation of previous study [6]. For a water jet pump the flow within it is a very complex flow. To analyse the water jet pump using CFD, the following assumptions are made: (i) the flow within the jet pump is steady icompressible. (ii) there is no heat transfer between water and surroundings, (iii) the surface roughness is taken as zero $(K=0)$, and (iv) the effect of buoyancy is ignored.

For incompressible flow the Reynolds-averaged continuity equation and momentum equation are as follows:

$\frac{\partial\left(u_{i}\right)}{\partial x_{i}}=0$

$\rho \frac{\partial\left(\mathrm{u}_{\mathrm{i}} \mathrm{u}_{\mathrm{j}}\right)}{\partial \mathrm{x}_{\mathrm{j}}}=\frac{\partial}{\partial \mathrm{x}_{\mathrm{j}}}\left[\mu \frac{\partial \mathrm{u}_{\mathrm{i}}}{\partial \mathrm{x}_{\mathrm{j}}}\right]+\frac{\partial \mathrm{\tau}_{\mathrm{ij}}}{\partial \mathrm{x}_{\mathrm{j}}}-\frac{\partial \mathrm{P}}{\partial \mathrm{x}_{\mathrm{i}}}$

Where; the Reynolds stress is:

$\tau_{\mathrm{ij}}=-\rho \overline{\mathrm{u}_{\mathrm{i}} \grave{\mathrm{u}}_{\mathrm{j}}}=\mu_{\mathrm{t}}\left[\frac{\partial \mathrm{u}_{\mathrm{i}}}{\partial \mathrm{x}_{\mathrm{j}}}+\frac{\partial \mathrm{u}_{\mathrm{j}}}{\partial \mathrm{x}_{\mathrm{i}}}\right]-\frac{2}{3} \mathrm{k} \rho \delta_{\mathrm{ij}}$

The transition SST turbulence model is a four equation turbulence model which is based on the coupling of the SST $\mathrm{k}-\omega$ model with the $\gamma-\mathrm{Re}_{\theta}$ model. In the transition SST model four transport equations are defined as below. The transport equation for the intermittency $\gamma$, which is a probability measure that a given point is located inside the turbulent region, is:

$$
\begin{aligned}
& \frac{\partial(\rho \gamma)}{\partial \mathrm{t}}+\frac{\partial\left(\rho \mathrm{u}_{\mathrm{j}} \gamma\right)}{\partial \mathrm{x}_{\mathrm{j}}}=-\mathrm{E}_{\gamma 1}+\mathrm{P}_{\gamma 1}-\mathrm{E}_{\gamma 2}+\mathrm{P}_{\gamma 2}+ \\
& \frac{\partial}{\partial \mathrm{x}_{\mathrm{j}}}\left[\left(\mu+\frac{\mu_{\mathrm{t}}}{\sigma_{\mathrm{y}}}\right) \frac{\partial \gamma}{\partial \mathrm{x}_{\mathrm{j}}}\right]
\end{aligned}
$$

Where; $\left(\mathrm{E}_{\gamma 1}\right.$ and $\left.\mathrm{P}_{\gamma 1}\right)$ are transition sources and $\left(\mathrm{E}_{\gamma 2}\right.$ and $\mathrm{P}_{\gamma 2}$ ) are destruction / relaminarization sources. The transport equation for transition momentum thickness Reynolds number $\widetilde{R}_{\theta t}$, which indicates the transition onset criteria, is:

$$
\frac{\partial\left(\rho \widetilde{R} e_{\theta t}\right)}{\partial t}+\frac{\partial\left(\rho u_{j} \widetilde{R} e_{\theta t}\right)}{\partial x_{j}}=P_{\theta t}+\frac{\partial}{\partial x_{j}}\left[\sigma_{\theta t}\left(\mu+\mu_{t}\right) \frac{\partial \widetilde{R} e_{\theta t}}{\partial x_{j}}\right]
$$

Where; $\left(\mathrm{P}_{\theta t}\right)$ is the source term.

The turbulence kinetic energy $\mathrm{k}$ and the specific dissipation rate $\omega$ transport equations are:

$$
\frac{\partial}{\partial \mathrm{x}_{\mathrm{j}}}\left(\rho \mathrm{u}_{\mathrm{j}} \mathrm{k}\right)=-\widetilde{\mathrm{D}}_{\mathrm{k}}+\gamma_{\mathrm{eff}} \widetilde{\mathrm{P}}_{\mathrm{k}}+\frac{\partial}{\partial \mathrm{x}_{\mathrm{j}}}\left[\left(\mu+\sigma_{\mathrm{k}} \mu_{\mathrm{t}}\right) \frac{\partial \mathrm{k}}{\partial \mathrm{x}_{\mathrm{j}}}\right]
$$

Where; $\left(\widetilde{\mathrm{D}}_{\mathrm{k}}\right.$ and $\left.\widetilde{\mathrm{P}}_{\mathrm{k}}\right)$ are the destruction and production terms for the turbulence model and the terms are:

$$
\begin{aligned}
& \widetilde{\mathrm{D}}_{\mathrm{k}}=\min \left(\max \left(\gamma_{\mathrm{eff}}, 0.1\right), 1.0\right) \mathrm{D}_{\mathrm{k}} \\
& \widetilde{\mathrm{P}}_{\mathrm{k}}=\min \left(\mathrm{P}_{\mathrm{k}}, 10 \beta \rho * \mathrm{k} \omega\right) \\
& \mathrm{D}_{\mathrm{k}}=\beta \rho * \mathrm{k} \omega
\end{aligned}
$$


$\frac{\partial}{\partial \mathrm{x}_{\mathrm{j}}}\left(\rho \mathrm{u}_{\mathrm{j}} \omega\right)=\alpha \frac{\widetilde{\mathrm{P}}_{\mathrm{k}}}{\mathrm{v}_{\mathrm{t}}}+\mathrm{Cd}_{\mathrm{w}}-\mathrm{D}_{\mathrm{w}}+\frac{\partial}{\partial \mathrm{x}_{\mathrm{j}}}\left[\left(\mu+\sigma_{\mathrm{w}} \mu_{\mathrm{t}}\right) \frac{\partial \omega}{\partial \mathrm{x}_{\mathrm{j}}}\right]$

Where; $\left(\mathrm{Cd}_{\mathrm{w}}\right.$ and $\left.\mathrm{D}_{\mathrm{w}}\right)$ are the cross-diffusion term for $\omega$ and the dissipation term, respectively.

The relationships among the Reynolds stress, turbulent viscosity and turbulence equations in the transition SST model could be summarized as follows. For incompressible flow the Reynolds stresses based on Boussinesq approximation and turbulent viscosity are defined as:

$\tau_{\mathrm{ij}}=-\rho \overline{\mathrm{u}_{\mathrm{i}} \grave{\mathrm{u}}_{\mathrm{j}}}=\mu_{\mathrm{t}}\left[\frac{\partial \mathrm{u}_{\mathrm{i}}}{\partial \mathrm{x}_{\mathrm{j}}}+\frac{\partial \mathrm{u}_{\mathrm{j}}}{\partial \mathrm{x}_{\mathrm{i}}}\right]$

$\mu_{\mathrm{t}}=\frac{\mathrm{k} \rho}{\omega} \frac{1}{\max \left[\frac{1}{\alpha^{*}, \mathrm{~F}_{2} \mathrm{~S}}\right]}$

Where; $\left(\mathrm{F}_{2}, \mathrm{~S}, \alpha^{*}\right.$ and $\left.\mathrm{a}_{1}\right)$ are a blending function, the strain rate magnitude, the turbulent viscosity damping factor and the model constant, respectively.

The transition SST Model details can be obtained from Menter et al. ([15] and [16]) and Langtry et al. [17].

Due to the rotational symmetry of the axial-jet pump, only a half of the pump is used as the computational domain instead of simulating the whole pump. The rotational-symmetry boundary condition is applied for the fluid zone. Hybrid mesh generation is performed with ANSYS Fluent Meshing. Around 21209 cells were needed for the pump to obtain mesh independent solutions. Inflated mesh is used near the wall boundaries to improve the boundary layer simulation accuracy. Layers of prismatic inflation cells are first generated separately in the inflated meshing process, from 2 to 8 layers in the near-wall region. In each layers case a first layer height of $45 \mathrm{~mm}$ and a growth rate of 1.2 were used. The $2 \mathrm{D}$ double-precision pressure based solver type was selected for a better resolution of the turbulent flow field. In the present numerical simulation study, the motive and entrained fluids total pressures are set as the pressure inlet boundary conditions and mixed total flow static pressure is set as the pressure outlet boundary condition. The turbulence intensity, and also the intermittency are used for all models for the transition SST turbulence model in order to specify the turbulence boundary conditions. The intermittency is set to 1 and the turbulence intensity is set to $5 \%$ in the computations for the SST model at the inlets and outlet of the axial- jet pump.

In the present CFD analysis, the coupled solution algorithm for the pressure velocity coupling, the least squares cell-based method for gradients evaluation and second-order schemes for spatial discretization are selected. Thus, all model and governing equations are solved using the second-order schemes. The calculated mass flow rates of entrained, motive and mixed fluids for water jet pump for a given scale and roughness depend on the entered values of the boundary conditions. The under relaxation factors are decreased slowly until reaching converged solution when the computations become unstable. By setting the convergence criteria for all the equations first to $10^{-4}$ and then $10^{-5}$, the numerical solutions can be obtained. The comparison between the results for these criteria showed unimportant differences between them. The effects of geometrical and operational parameters on axial-jet pump performance are investigated in detail after completing the flow modelling in the pump using the ANSYS Fluent R 15.0 code.

\section{EXPRIMENTAL TEST RIG}

The experimental work in the present study is carried out to provide experimental data for extensive model validation and optimum model verification. This will be achieved by constructing a test rig including axial-water jet pump test model in the Fluid Mechanics Laboratory of the Mechanical Power Engineering Department, Faculty of Engineering, Minoufiya University, Egypt. The principal objective of this work is to study the effect of the major controlling parameters that have direct effects on the axial jet pump performance. These parameters are the inflow motive pressure and nozzle spacing.

A schematic diagram of the experimental test rig is shown in Fig. 2. The test rig consists of three tanks, orifice meter, centrifugal pump, jet pump, pressure gages, u-tube manometer, multi-tube manometer and piping system.

The test rig including axial jet pump test model was held in a manner that enabling change nozzle relative position of jet pump. The present experimental test rig was modified three times in order to obtain three relative positions of a values of $\mathrm{Z}=0,1$ and 


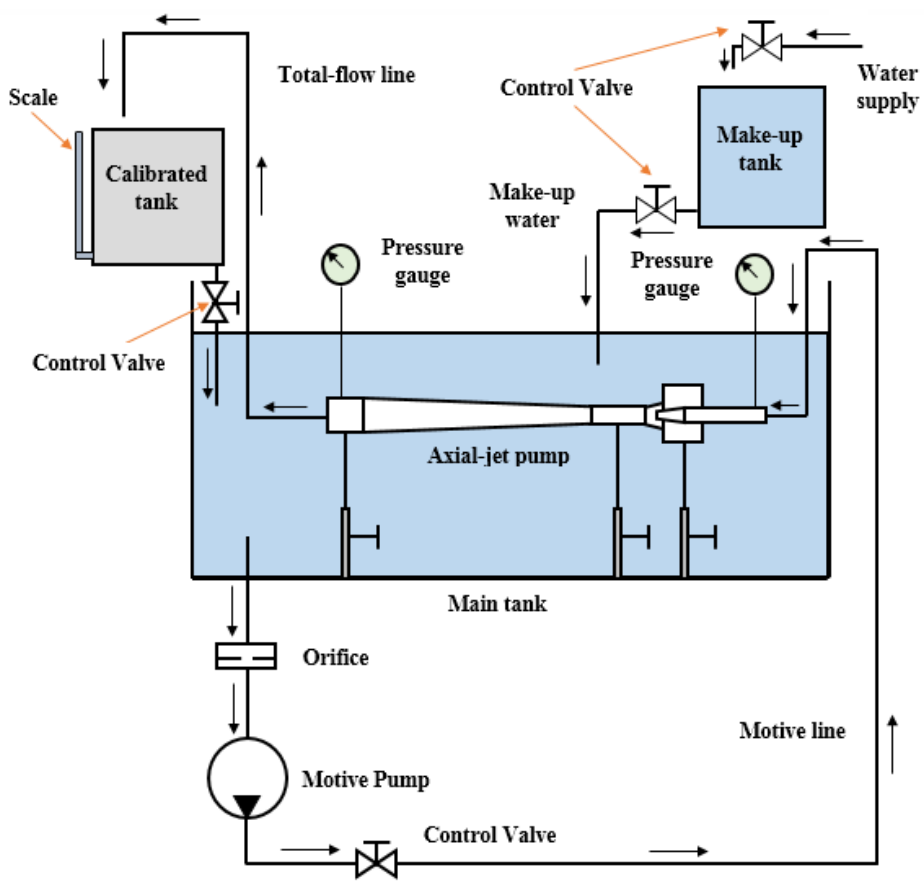

Figure 2 Schematic diagram of the experimental test rig.

In determining and comparing the performance of all jet pumps dimensionless parameters, which are the ratios of various properties, are used. These parameters for liquid jet pumps are defined as follows:

(i) Mass Flow Ratio $\left(\mathrm{M}_{\mathrm{r}}\right)$

The mass flow ratio; the ratio between the entrained (secondary) fluid mass flow rate and motive fluid mass flow rate, and it can be represented as the following:

$\mathrm{M}_{\mathrm{r}}=\frac{\dot{\mathrm{m}}_{\mathrm{s}}}{\dot{\mathrm{m}}_{\mathrm{m}}}$

(ii) Pressure Ratio $\left(\mathrm{P}_{\mathrm{r}}\right)$

The pressure ratio; the ratio of the increase in total pressure of entrained (secondary) flow to the decrease in total pressure of motive flow, and it can be represented as the following:

$\mathrm{P}_{\mathrm{r}}=\frac{\left(\mathrm{P}_{\mathrm{dt}}-\mathrm{P}_{\mathrm{st}}\right)}{\left(\mathrm{P}_{\mathrm{mt}}-\mathrm{P}_{\mathrm{dt}}\right)}$

\section{(iii) Efficiency ( $\eta$ )}

The jet pump efficiency; the ratio of the total energy increase of entrained (secondary) flow to the total energy decrease of driving flow, and it can be obtained by multiplying mass flow ratio by pressure ratio.

$\eta=M_{r} \cdot P_{r}$
In this simulation study, validation was held between CFD, 2D present results and (experimental - CFD, 3D) data [6] at the same 1/1-scale jet pump dimensions. Fig. 3 -( $a$ and $b)$ shows the experimental and numerical results of the pump efficiency and pressure ratio with mass flow ratio. Fig. (3-a) illustrates that the pump efficiency increases, showing a peak at about $\mathrm{Mr}=1.7$ and then decreases with increasing mas flow rate ratio.

Fig. (3-b) shows that the pressure ratio in jet pumps decreases almost linearly with increase in mass flow ratio. This is an expected behaviour because relatively more energy of the motive fluid is transferred to the entrained fluid for more of the fluid being pumped. In addition, the present $2 \mathrm{D}$ numerical results are relatively in close agreement with the experimental and $3 \mathrm{D}$ numerical results obtained by [6] in the region of mass flow ratio up to 1.7. However, for mass flow ratio more than 1.7 the present $2 \mathrm{D}$ numerical results gives higher efficiency than those of [6]. Moreover, Fig. 3 shows that the numerical $2 \mathrm{D}$ results using transition SST turbulence model shows a good agreement with experimental data and theoretical 3D data using transition SST turbulence model. Therefore, CFD, 2D technique is used in this investigation which saves computational time and cost. Also, it helps in saving efforts exerted in laboratories in order to predict one or more geometrical and operational parameters. 


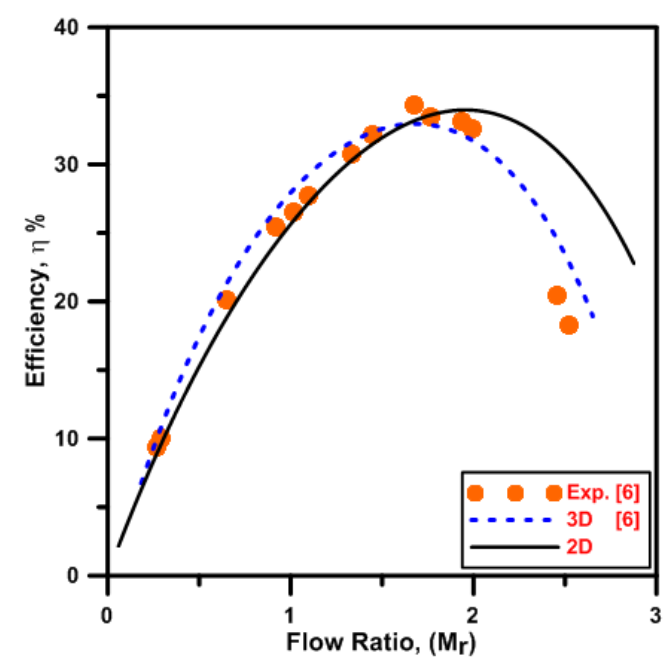

(a)

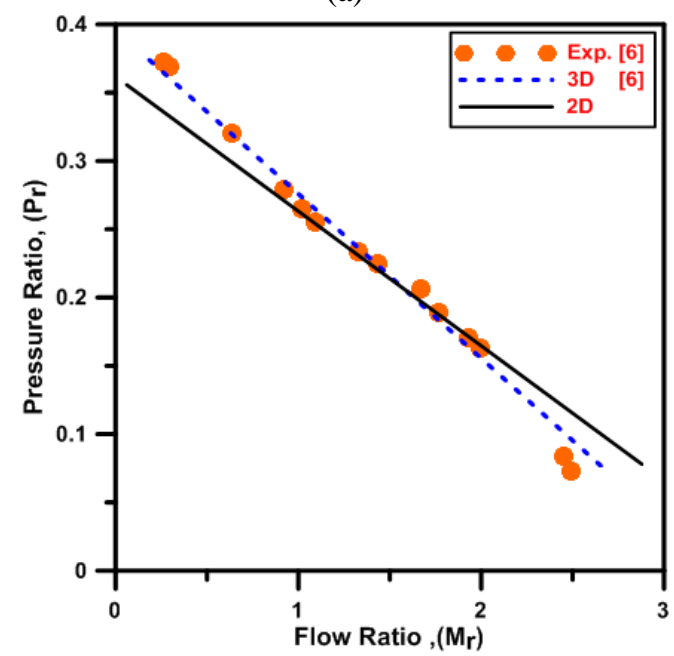

(b)

Figure 3 Comparison between the present CFD, 2D results and (experimental - CFD, 3D) data [6].

The variations of the pressure and velocity across the centreline of the pump with the distance from the pump inlet at the same 1/1 scale pump are shown in Fig.4-(a and $b$ ).

Fig.4 shows the results of present numerical 2D and numerical 3D data [6].

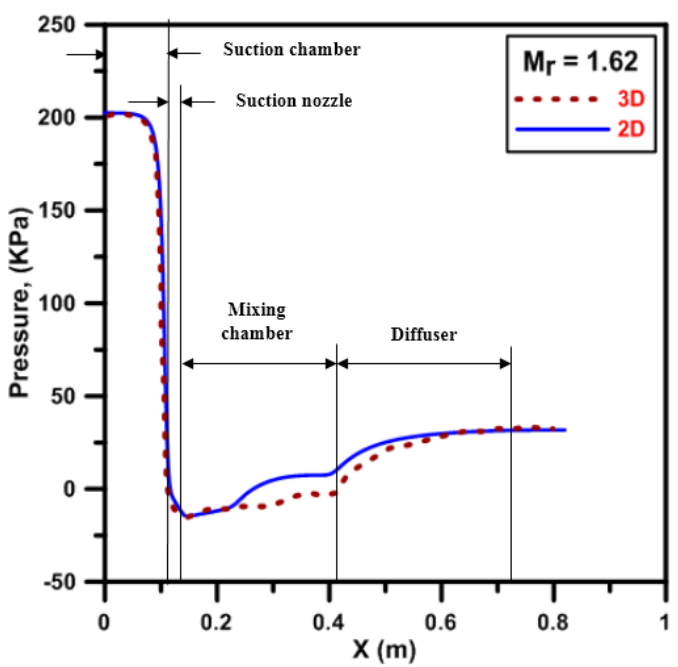

(a)

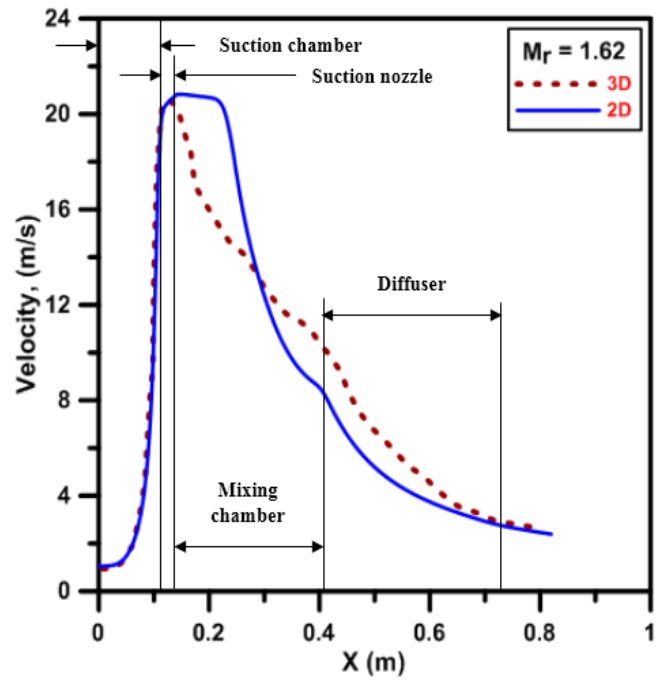

(b)

Figure 4 Comparison between the present numerical, $2 \mathrm{D}$ results and numerical, $3 \mathrm{D}$ data [6].

Uncertainty analysis should be conducted on all data collected from all measurements in order to quantify the data and validate the accuracy, see Table 1.

Table 1 Uncertainty for performance parameters of the axial-water jet pump.

\begin{tabular}{||l|c|c|}
\hline \multirow{2}{*}{\multicolumn{1}{|c|}{ Parameter }} & \multicolumn{2}{c|}{ Percentage uncertainty $( \pm \%)$} \\
\cline { 2 - 3 } & Min. uncertainty & Max. uncertainty \\
\hline \hline Total discharge of jet pump $\left(\mathrm{Q}_{\mathrm{t}}\right)$ & 0.571 & 1.01 \\
\hline Motive discharge for jet pump $\left(\mathrm{Q}_{\mathrm{m}}\right)$ & 0.613 & 1.12 \\
\hline Efficiency of jet pump & 0.145 & 0.698 \\
\hline
\end{tabular}




\section{Nasr, M.A. Hosien, E.M. Wahba and A.A.A. Sheha "COMPUTATIONAL AND EXPER..."}

\section{RESULTS AND DISCUSSION}

A comparison between the experimental and numerical results are illustrated and discussed in this section. The comparisons are conducted at the same geometries and the same operating conditions.

\subsection{Velocity Distribution and Streamlines}

The streamlines at three different flow ratios of 0.16 , 1.19 and 2 are plotted in the half symmetry plane as shown in Figs. 5-(a, b and c). Small eddies after the exit of suction nozzle and larger eddies near the wall in the entry section of the mixing chamber are formed at lower mass flow ratios as shown in Fig. (5a). A higher pressure ratio and hence a higher outlet (back) pressure at lower flow ratios is resulted due to the formation of these eddies. Although the jet velocity at the nozzle outlet is very high, it drops suddenly near the middle of the mixing chamber as observed from the Fig. (5-a). The reason for this low mass flow ratio is that a large amount of the water jet energy is lost in the eddy formation and thus, less mechanical energy from the motive water is transferred to the entrained water. Moreover, the entity of smaller eddies in the outer region between the mixing chamber wall and the jet blow out of the motive nozzle. In other words, the entrained fluid route have an influence on decreasing jet pump mass flow rate. These effects reduce the jet pump efficiency in lower flow ratios. The secondary flow is entrained properly to the mixing chamber without leading to eddies and separations at the optimum mass flow ratio $\mathrm{M}_{\mathrm{r}}=1.19$, as shown in Fig. (5-b). The velocity of motive flow decreases gradually and the velocity of the entrained water increases along the mixing chamber at the same time due to the jet from the motive nozzle. So, the kinetic energy of the motive water jet throughout the pipe is transferred to the secondary fluid without causing additional energy losses. Thus, the jet pump efficiency at the mentioned flow ratio reaches a maximum value.

At higher mass flow ratios $\left(M_{r}=2\right)$ there is a drop in efficiency. This drop can be explained as follows: At the outlet of mixing chamber or the inlet of diffuser the flow velocity is high and the main flow toward the diffuser outlet does not fill the cross-section of the pipe completely, as shown in Fig. (5-c). So, the pressure does not rise sufficiently in the diffuser due to the smaller eddies generated by this type of flow. It can be concluded that in such operating conditions a lower pressure ratio and reduced efficiency occur.

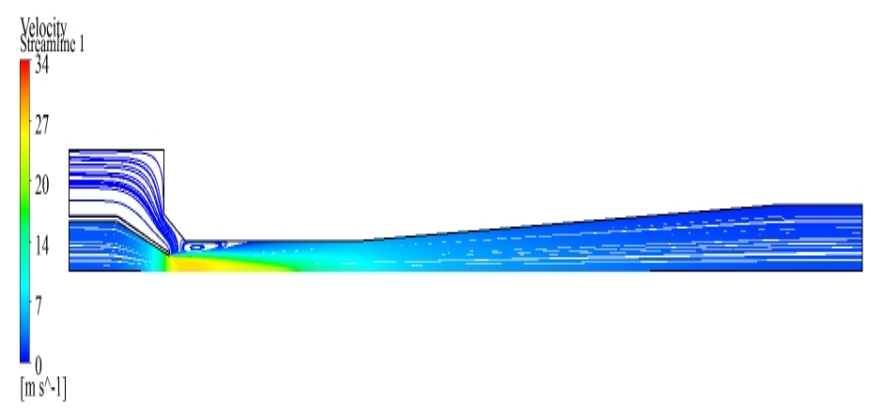

a) $\mathrm{M}_{\mathrm{r}}=0.16$

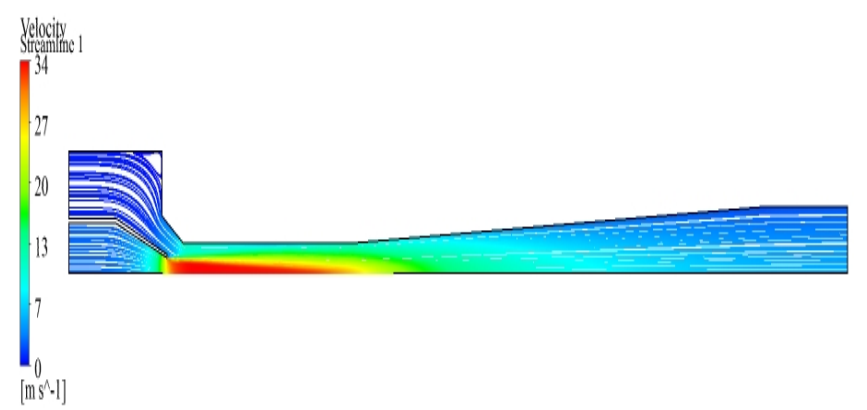

b) $\mathrm{M}_{\mathrm{r}}=1.19$

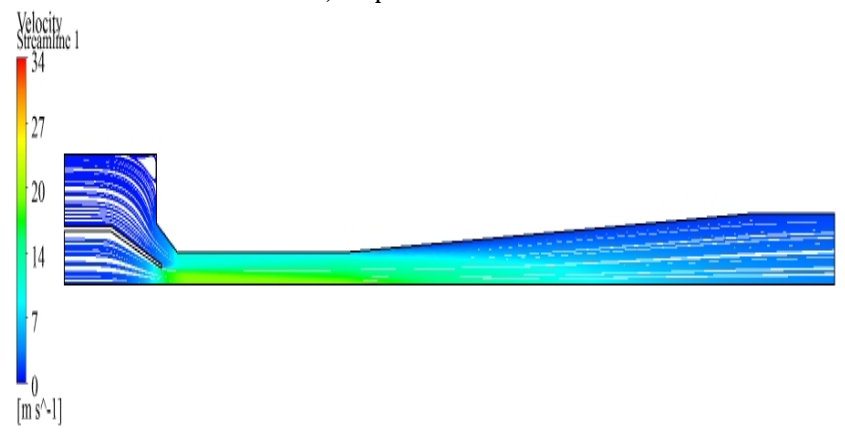

c) $\mathrm{M}_{\mathrm{r}}=2$

Figure 5 Velocity distribution and streamlines at different mass flow ratios for scale (1/1) jet pump at which the obtained maximum theoretical efficiency $\left(A_{r}=0.271\right)$.

As shown in Figs. 6-(a and b), the pressure and velocity variations along the central axis of the jet pump are presented. At the lower flow ratio $\mathrm{M}_{\mathrm{r}}=0.16$, the liquid pressure rises sharply at slightly ahead of the mixing chamber inlet, due to a higher back (exit) pressure acting on the pump. So, the mass flow rate of the entrained liquid drops due to the previous flow behaviour. Although the pump inlet pressures for the lower and higher flow ratios differ, the pressure value for the optimum flow ratio is higher than the pressure for the higher flow ratio along suction chamber. As shown in Fig. (6-a) the pressure for the optimum flow ratio drops to a value lower than the pressure for the higher flow ratio along the suction nozzle and mixing chamber inlet and then increases suddenly along the mixing chamber exit and diffuser. The velocity 
distribution trends along the centreline of the pump, as expected, become opposite of the pressure distribution trends, as shown in Fig. 6-(a and b).

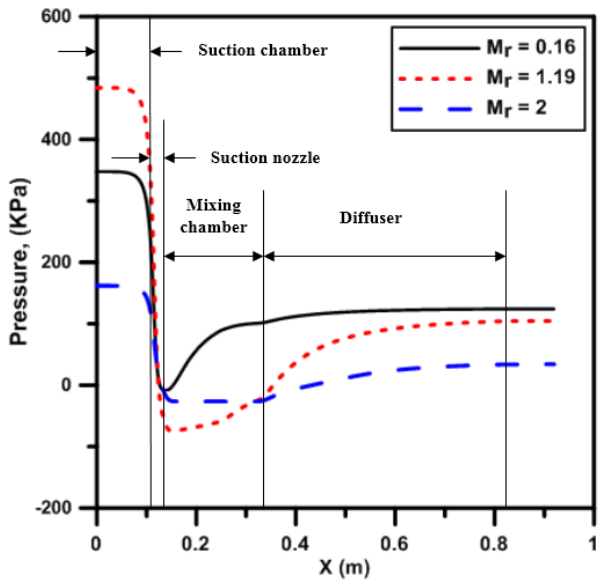

(a)

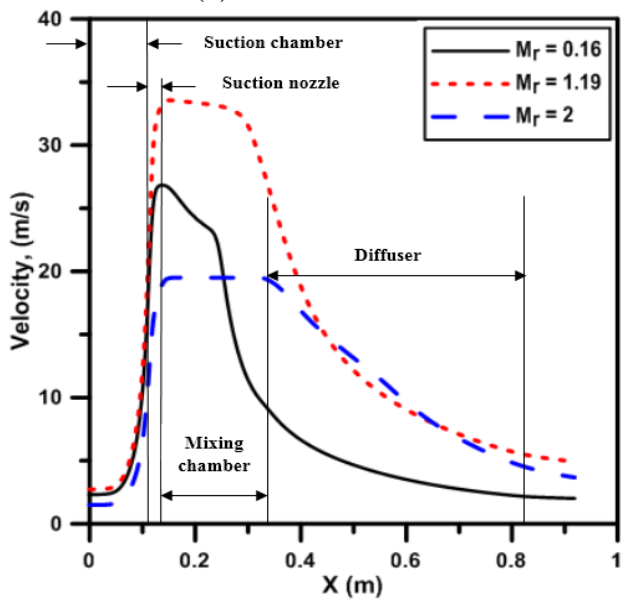

(b)

Figure 6 Pressure (a) and velocity (b) variations along centreline of jet pump.

\subsection{Jet Pump Wall Pressure Distribution}

A comparison between experimental and theoretical results generated by the commercial software, the ANSYS R 15.0 FLUENT at the same geometries and the same operating conditions is carried out.

The experimental test pump here is manufactured using the optimum mixing chamber relative length $(\mathrm{L}=5.48)$, the optimum angle of diffuser of $\left(\theta_{\text {dif. }}=5^{\circ}\right)$ and area ratio $\left(A_{r}=0.271\right)$ at which maximum numerical efficiency occurs that obtained from numerical investigation.
Figs. 7-(a, b and c), show the measured experimental pressure values along the outer wall of jet pump experimental test model and theoretical pressure values calculated numerically at various flow ratios ranged from 0.035 to 1.9 with the same nozzle relative position of $\mathrm{Z}=0,1$ and 2 . The comparison shows good agreement between the results obtained experimentally and numerically along the mixing chamber section. However in the diffuser section the agreement is fair for higher mass flow ratios. Unfortenully, the agreement is to some extent weak at lower mass flow ratios for all the used values of the relative positions $(\mathrm{Z})$.

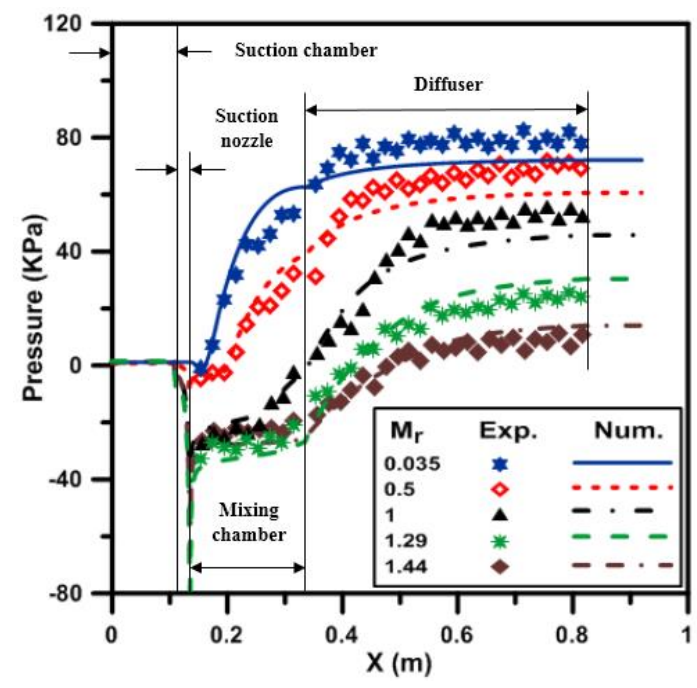

(a) $Z=0$

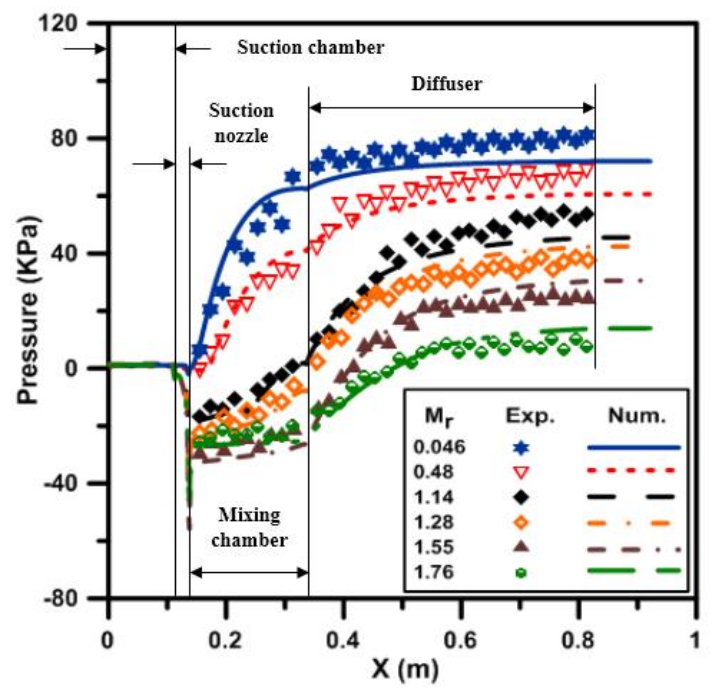

(b) $Z=1$ 


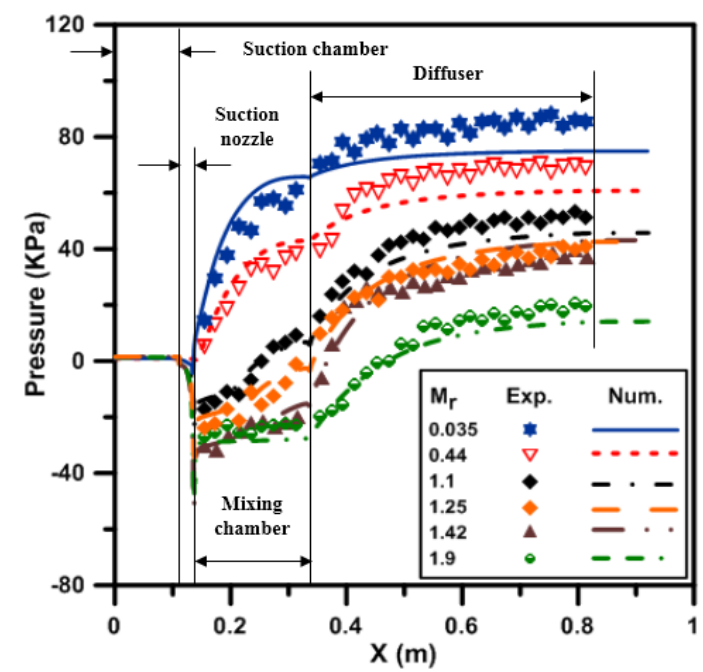

(c) $\mathrm{Z}=2$

Figure 7-(a, b and c) Comparison between experimental and numerical pressure variations along the outer wall of jet pump.

4.3. Comparison Between Experimental and Numerical Efficiency and Head Ratio Curve

Comparison between experimental and numerical results of both the efficiency and head ratio at various flow ratios with different relative positions of 0,1 , and 2 are given in Fig. 8 and Fig. 9 respectively. The comparison between the experimental and numerical values is in good agreement.

Either experimental or numerical results showed that the lowest efficiency corresponds to the smallest nozzle relative position of $(Z=0)$, and the highest efficiency is attained at $(Z=1)$, as seen in Fig. 8

In addition the position of the maximum efficiency is shifted to the right at increasing the relative position of nozzle.

Fig. 9 shows the experimental and numerical results of the variation of pressure ratio with mass flow ratio at different nozzle relative positions. This Figure shows that the head ratio decreases almost linearly with the increase of the mass flow ratio larger than 0.4.

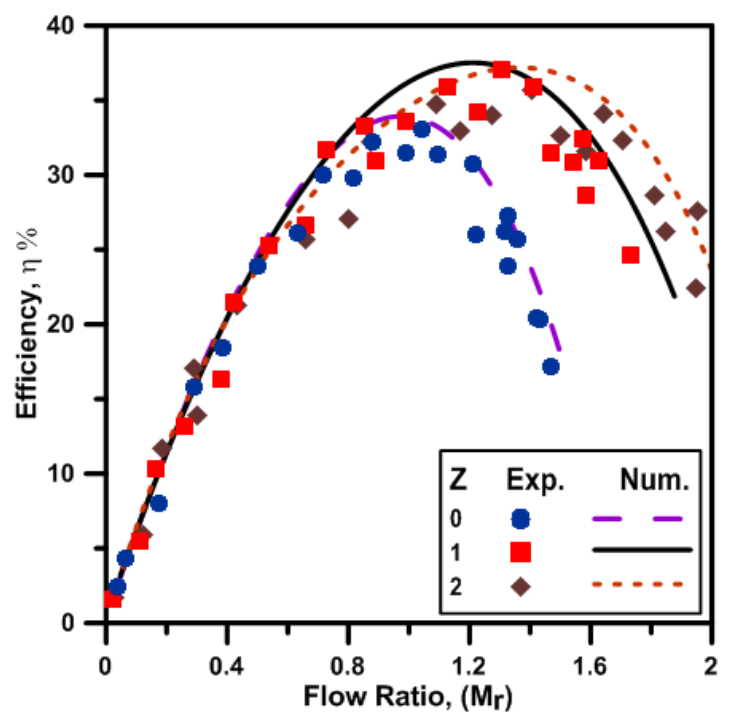

Figure 8 Comparison between experimental and numerical data for the three relative positions; efficiency curve.

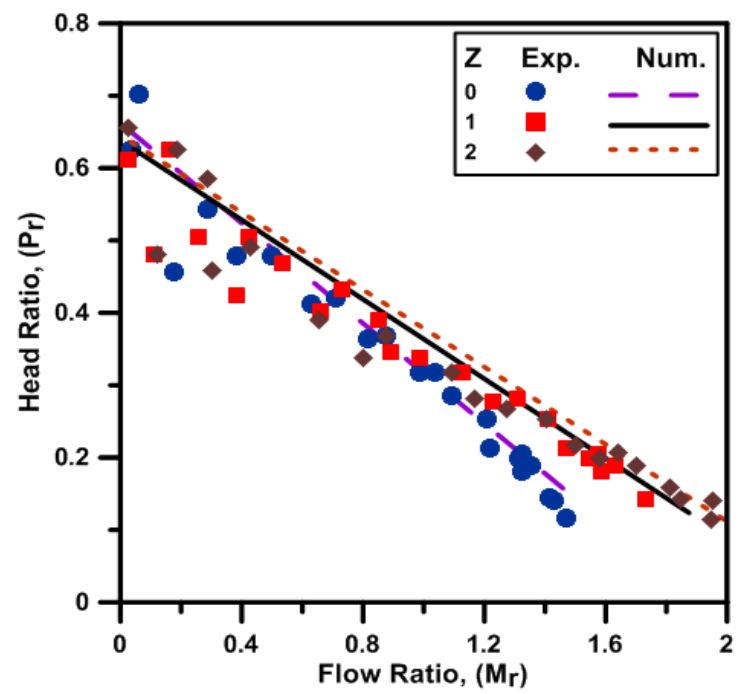

Figure 9 Comparison between experimental and numerical data for the three relative positions; head ratio curve. 


\section{Conclusions}

The important conclusions that can be drawn are as follows:

1. In the flow simulation study, the optimization of thirty five different water jet pumps having diffuser angles in the range of $\left(2.5^{\circ}-9^{\circ}\right)$, relative lengths of mixing chamber in the range of (3.32-7.4) and area ratios in the range of $(0.108-0.331)$ were carried out using the transition SST turbulence model in 2D technique.

2. For the purpose of validation, the numerical results for $2 \mathrm{D}$ and $3 \mathrm{D}$ of the optimization work were compared with the optimized experimental results at the boundary conditions in the literature optimum operating conditions. The numerical, 2D results relative to the experimental results and numerical, 3D results showed a good agreement and results remained approximately within the same range for the efficiency of the similar water jet pump. Thus, the CFD simulation, 2D results obtained by the transition SST model were validated with experimental data and numerical, 3D data using the same model. Although the transition SST turbulence model generally slightly underestimates the optimum efficiency, it provides detailed insight into geometrical effects in the water jet pumps.

3. The optimum numerical design curves generated in the study may be used in designs of water jet pumps. The numerical results obtained showed that the optimum value for diffuser angle at which the efficiency is a maximum value is $5^{\circ}$. Furthermore, the optimum relative length of mixing chamber is $(\mathrm{L}=$ 5.48).

4. The highest efficiency of $37.82 \%$ was determined by transition SST turbulence model for the area ratio of $\left(A_{r}=0.271\right)$, mixing chamber relative length $(L=5.48)$, diffuser angle $\left(\theta_{\text {dif. }}=5^{\circ}\right)$, relative position of the nozzle $(Z=1)$, flow ratio of $\left(M_{r}=\right.$ 1.19), and pressure ratio of $\left(\mathrm{P}_{\mathrm{r}}=0.317\right)$.

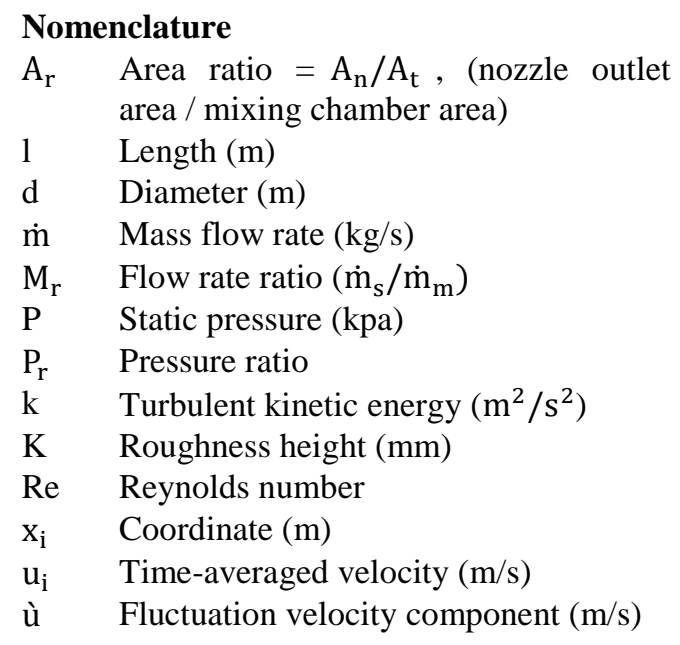

$\mathrm{x}_{\mathrm{n}} \quad$ Driving nozzle position (m)

$\mathrm{X} \quad$ Distance from the jet pump inlet (m)

$\mathrm{Z} \quad$ Relative position of driving nozzle

L Relative length of mixing chamber

Greek letters

$\varepsilon \quad$ Turbulent kinetic energy dissipation $\left(\mathrm{m}^{2} / \mathrm{s}^{3}\right)$

$\eta \quad$ Jet pump efficiency

$\rho \quad$ Fluid density $\left(\mathrm{kg} / \mathrm{m}^{3}\right)$

v Kinematic viscosity $\left(\mathrm{m}^{2} / \mathrm{s}\right)$

$\omega$ Specific turbulent dissipation rate $\left(\mathrm{s}^{-1}\right)$

$\mu \quad$ Dynamic viscosity (Pa.s)

$\mu_{\mathrm{t}} \quad$ Turbulent viscosity (Pa.s)

\section{Subscripts}

$\begin{array}{ll}\mathrm{d} & \text { Discharge /outlet } \\ \mathrm{n} & \text { Nozzle } \\ \mathrm{m} & \text { Motive /primary fluid } \\ \mathrm{t} & \text { Mixing pipe, total } \\ \mathrm{s} & \text { Suction, smooth } \\ \mathrm{dif} & \text { Diffuser } \\ \text { exp. } & \text { Experimental }\end{array}$

\section{References}

[1] Chamlong, P., and Aoki, K., 2002, "Numerical Prediction on the Optimum Mixing Throat Length for Drive Nozzle Position of the Central Jet Pump", Proceedings of Tenth international symposium on flow visualization, August 26-29, Kyoto, Japan.

[2] Hammoud, A. H., 2006, " Effect of Design and Operational Parameters on Jet Pump Performance ", Proceedings of the 4th WSEAS International Conference on Fluid Mechanics and Aerodynamics, Elounda, Greece, August 21-23, pp. 245252.

[3] El-Sawaf, I. A., Halawa, M. A., Younes, M. A., and Teaima, I. R., 2011, " Study of the Different Parameters That Influence on the Performance of Water Jet Pump ", Fifteenth International Water Technology Conference, IWTC 15, Alexandria, Egypt.

[4] Vyas, B.D., and Kar, S., 1972, "Standardization of water jet pumps", Proc., Symp. on jet Pumps and ejectors, paper 10, London, U.K., PP. 155-170. 
[5] Teaima, I. R., and Meakhail, T. A., 2013, " A Study of the Effect of Nozzle Spacing and Driving Pressure on the Water Jet Pump Performance", International Journal of Engineering Science and Innovative Technology (IJESIT), September, Volume 2, Issue 5.

[6] Aldas, K., and Yapici, R., 2014, " Investigation of Effects of Scale and Surface Roughness on Efficiency of Water Jet Pumps Using CFD", Engineering Applications of Computational Fluid Mechanics, Vol. 8, No. 1, pp. 14-25.

[7] Cunningham, R.G., and Dopkin, R.J., 1974, "Jet Breakup and Mixing Throat Lengths for the Liquid Jet Gas Pump", J. Fluid Engineering, Trans. ASME, 93(3):216-226.

DOI: $10.1115 / 1.3447144$

[8] Prabkeao, C., and Aoki. K., 2005, "Study on the Optimum Mixing Throat Length for Drive Nozzle Position of the Central Jet Pump", Journal of Visualization, 8(4):347-355.

[9] Hansen, A.G., and Kinnavy, R., 1965 "The design of water jet pumps Part-IExperimental determination of optimum design parameters" ASME paper 65WA/FE-31.

[10] El Hayek, M. D., and Hammoud, A. H., 2006, " Prediction of Liquid Jet Pump Performance Using Computational Fluid Dynamics ", Proceedings of the 4th WSEAS International Conference on Fluid Mechanics and Aerodynamics, Elounda, Greece, August 21-23, pp. 148153.

[11] Winoto, S.H., Li H., and Shah, D.A., 2000, "Efficiency of Jet Pumps", Journal of Hydraulic Engineering, 126(2):150156. DOI: 10.1061/ (ASCE) 07339429(2000)126:2(150).

[12] Zou, C.H., Tang, H.Li.P., and Xu, D.H., 2015 "Effect of structural forms on the performance of a jet pump for a deep well jet pump ", National Research Center of Pumps and Pumping System Engineering and Technology, Jiangsu Unversity, China, Vol 59, pp. 257-266.

[13] Brijesh, R.N., Sagar, M.P., 2016 "The Effect of Venturi Design on Jet Pump Performance", Journal for Research, Volume 02, Issue 04, June, pp. 23-28.

[14] Xiaogang, D., Jingliang, D., Zhentao, W., and Jiyuan, T., 2017 "Numerical analysis of an annular water-air jet pump with self-induced oscillation mixing chamber", The Journal of Computational Multiphase Flows, pp. 1-7.

[15] Menter, F.R., Langtry, R.B., Likki, S.R., Suzen, Y.B., Huang, P.G., and Völker, S., 2004, "A Correlation Based Transition Model Using Local Variables, Part 1-Model Formulation", In Proceedings of the ASME Turbo Expo. Vienna, Austria, June14-17, paper no. GT2004-53452.

[16] Menter, F.R., Langtry, R.B. and Völker, S., 2006, "Transition Modeling for General Purpose CFD Codes", Flow Turbul. Combust. 77(1-4): 277-303.

[17] Langtry, R.B., Menter, F.R., Likki, S.R., Suzen, Y.B., Huang, P.G., Völker, S., 2004, "A correlation-Based Transition Model Using Local Variables, Part 2-Test Cases and Industrial Applications", In Proceedings of the ASME Turbo Expo. Vienna, Austria, June 14-17, paper no. GT2004-53454. 